\title{
A practical approach to lake water density from electrical conductivity and temperature
}

\author{
Santiago Moreira ${ }^{1,2,3}$, Martin Schultze ${ }^{1}$, Karsten Rahn ${ }^{1}$, and Bertram Boehrer ${ }^{1}$ \\ ${ }^{1}$ UFZ-Helmholtz-Centre for Environmental Research, Department Lake Research, Brueckstrasse 3a, 39114 Magdeburg, \\ Germany \\ ${ }^{2}$ Laboratoire des Sciences du Climat et de l'Environnement, LSCE/IPSL, CEA-CNRS-UVSQ, Université Paris-Saclay, \\ 91191 Gif-sur-Yvette, France \\ ${ }^{3}$ Institute of Hydrobiology, TU-Dresden, Zellescher Weg 40, 01217 Dresden, Germany
}

Correspondence to: Santiago Moreira (santiago.moreira-martinez@1sce.ipsl.fr)

Received: 22 January 2016 - Published in Hydrol. Earth Syst. Sci. Discuss.: 17 February 2016

Revised: 3 June 2016 - Accepted: 20 June 2016 - Published: 22 July 2016

\begin{abstract}
Density calculations are essential to study stratification, circulation patterns, internal wave formation and other aspects of hydrodynamics in lakes and reservoirs. Currently, the most common procedure is the use of CTD (conductivity, temperature and depth) profilers and the conversion of measurements of temperature and electrical conductivity into density. In limnic waters, such approaches are of limited accuracy if they do not consider lake-specific composition of solutes, as we show. A new approach is presented to correlate density and electrical conductivity, using only two specific coefficients based on the composition of solutes. First, it is necessary to evaluate the lake-specific coefficients connecting electrical conductivity with density. Once these coefficients have been obtained, density can easily be calculated based on CTD data. The new method has been tested against measured values and the most common equations used in the calculation of density in limnic and ocean conditions. The results show that our new approach can reproduce the density contribution of solutes with a relative error of less than $10 \%$ in lake waters from very low to very high concentrations as well as in lakes of very particular water chemistry, which is better than all commonly implemented density calculations in lakes. Finally, a web link is provided for downloading the corresponding density calculator.
\end{abstract}

\section{Introduction}

Density is one of main physical quantities governing the hydrodynamics, stratification, and mixing in lakes and reservoirs. Water quality in lakes is controlled by biological and biogeochemical processes which depend on the availability of oxygen in deep waters and nutrients in surface waters. Both phenomena are controlled by the duration and extension of the turnover period, which is dependent on density gradients. Therefore, density is a very important variable in numerical models for the simulation of the behaviour of lakes under changing conditions, e.g. due to management measures or phenomena related to global climate change.

The density of lake water (at atmospheric pressure) depends on temperature and dissolved water constituents. Since temperature, chemical composition and concentrations may vary over time, from lake to lake or even within a particular lake due to seasonal stratification or meromixis, numerical models of lakes calculate the density internally. There are several approaches to calculate water density in lakes. Most of them are general equations that do not always reflect specific properties of lakes. If enough measurements of density for the relevant temperature range are available and composition and concentrations of the main constituents are constant, regressions can be used to generate a mathematical formula for density in a specific lake (e.g. Jellison et al., 1999; Vollmer et al., 2002; Karakas et al., 2003). If the composition is constant and the main constituents are ions, electrical conductivity or salinity may be used as an easy-to-measure 
proxy for concentrations (Bührer and Ambühl, 1975; Chen and Millero, 1986; Pawlowicz and Feistel, 2012).

Imboden and Wüest (1995) discussed the influence of dissolved substances on (potential) density because both the concentration and chemical composition of the total dissolved solids change considerably from lake to lake (see e.g. Boehrer and Schultze, 2008). The effects of dissolved solids on density stratification have been studied in lake-specific investigations in Lake Malawi (Wüest et al., 1996) and in Lake Matano (Katsev et al., 2010). In some cases, the specific contribution of ions such as calcium, carbonate or dissolved iron can control the permanent stratification in lakes such as in La Cruz (Spain) (Rodrigo et al., 2001), Cueva de la Mora (Spain) (Sanchez-España et al., 2009) or Waldsee (Germany) (Dietz et al., 2012).

Density of pure water can be calculated using mathematical expressions such as those in Kell (1975) or Tanaka et al. (2001). Density calculations of natural waters require additional terms to include the contributions of dissolved substances. Specific formulas have been developed for ocean conditions. The UNESCO equations developed by Fofonoff and Millard (1983) have been the standard for a long period. They used temperature and practical salinity based on electrical conductivity measurements. Because seawater conditions are a known reference and the approaches provide stable results over a wide range of temperatures and electrical conductivity, these have been applied in limnic systems and implemented in numerical models such as DYRESM (Imberger and Patterson, 1981; Gal et al., 2009), ELCOM (Hodges and Dallimore, 2007), GOTM (Burchard et al., 1999; Umlauf et al., 2005) or CE-QUAL-W2 (Cole and Buchak, 1995). Recently the ocean standard was replaced by the new Thermodynamic Equation of Seawater 2010 (TEOS-10; IOC et al., 2010). However, as the composition of solutes differs greatly from the ocean, density calculation based on ocean conditions can only be of limited accuracy. Pawlowicz and Feistel (2012) have considered the application of TEOS-10 (IOC et al., 2010) in several cases different from seawater, correcting the salinity values depending on the composition before applying TEOS-10 (IOC et al., 2010). Bührer and Ambühl (1975) developed an equation to calculate density based on temperature and specific conductance at $20^{\circ} \mathrm{C}$ for alpine lakes. In addition, a popular approach was formulated by Chen and Millero (1986) for tuning ocean approaches to freshwater conditions (salinity $<0.6 \mathrm{psu}$ ).

Higher accuracy can be achieved when site-specific density equations are produced. Jellison et al. (1999) developed a density equation for Mono Lake from water samples which have been measured at different temperatures and dilutions. In the case of meromictic lakes, strong differences in the composition of the mixolimnion and monimolimnion must be reflected in the density equations in order to sustain the permanent stratification in the density calculations. Boehrer et al. (2009) and von Rohden et al. (2010) used an equation based on density measurements of the monimolimnion and mixolimnion of the Waldsee.

Boehrer et al. (2010) evaluated the contribution of the different cations and anions separately in terms of partial molal volumes and implemented an algorithm, RHOMV (http: //www.ufz.de/webax), to calculate density with a secondorder approximation for temperature dependence and ionic strength dependence. Pawlowicz et al. (2011) implemented the LIMBETA method that calculates density from composition. Another approach comes from Pawlowicz et al. (2012) where the authors propose to use TEOS-10 but replace seawater salinity with specific salinities obtained and corrected for freshwaters. This limnic salinity can be calculated using the chemical composition by summing up all the dissolved solutes $\left(\mathrm{Sa}^{\text {soln }}\right)$ or by summing up only the dissolved ions $\left(\mathrm{Sa}^{\text {ionic }}\right)$ and correcting this value with the dissolved $\mathrm{Si}(\mathrm{OH})_{4}, \mathrm{Sa}^{\text {dens }}=\mathrm{Sa}^{\text {ionic }}+50.6 \times\left[\mathrm{Si}(\mathrm{OH})_{4}\right]$ $\left(\mathrm{mol} \mathrm{kg}^{-1}\right)$. Based on partial molal volumes (RHOMV), Dietz et al. (2012) separated the contributions of solutes for freshwater lakes. Moreira et al. (2011) based density on the composition of solutes in their model to reproduce the permanent stratification of the Waldsee numerically using RHOMV to include the reactivity of substances in the density (see also Nixdorf and Boehrer, 2015).

These prior studies therefore highlight the necessity of including the chemical composition to obtain an accurate calculation of density. However, we accept the need for a practical density approach, which can easily be implemented, such as a mathematical formula that relates density to temperature and electrical conductivity. In this manuscript, we develop coefficients for such a formula from the chemical composition. We provide an algorithm - RHO_LAMBDA (from $\rho_{\lambda}$ ) - to obtain such coefficients and demonstrate the applicability of the approach with water from Rappbode Reservoir. We also provide an appropriate assessment for the Rappbode Reservoir case and compare the accuracy with other approaches currently in use for limnic waters. For a quantitative judgement of the general applicability of our approach, we also evaluate coefficients for two further freshwater bodies (Lake Geneva, Lake Constance), an extremely saline lake (Mono Lake), a meromictic open pit lake in the mixolimnion and the monimolimnion (Waldsee), and finally seawater as a globally known example and well-defined standard.

\section{Methods: the proposed approach (RHO_LAMBDA)}

We propose a simple equation for density as a numerical approximation of the (potential) density of lake water:

$\rho \approx \rho_{\lambda}\left(T, \kappa_{25}\right)=\rho_{\mathrm{W}}(T)+\kappa_{25}\left[\lambda_{0}+\lambda_{1} \times\left(T-25^{\circ} \mathrm{C}\right)\right]$,

where the first term of the right side $\rho_{\mathrm{w}}$ is the density of pure water, which can be calculated in a very accurate way using Kell (1975) or Tanaka (2001). Our approach (Eq. 1) correlates density with temperature $(T)$ and electrical conductiv- 
ity at $25^{\circ} \mathrm{C}\left(\kappa_{25}\right)$ of a water sample using coefficients $\lambda_{0}$ and $\lambda_{1}$. The introduction of $\lambda_{1}$ reflects temperature dependence of the density contribution of the solutes, which is required for a shifting temperature of maximum density. Only two coefficients need to be determined, and thus this equation is easy to implement. Coefficients $\lambda_{0}$ and $\lambda_{1}$ can be obtained as follows.

At $T=25^{\circ} \mathrm{C}$, the $\lambda_{1}$ term in Eq. (1) vanishes and $\lambda_{0}$ can be calculated using Eq. (2) provided that the water density at $25^{\circ} \mathrm{C}$ is known from other sources:

$\lambda_{0}=\frac{\rho\left(T=25^{\circ} \mathrm{C}, \kappa_{25}\right)-\rho_{\mathrm{W}}\left(T=25^{\circ} \mathrm{C}\right)}{\kappa_{25}}$.

If the density is also known for a temperature $T \neq 25^{\circ} \mathrm{C}, \lambda_{1}$ can be calculated in a second step:

$\lambda_{1}=\frac{\left[\rho\left(T, \kappa_{25}\right)-\rho_{\mathrm{w}}(T)\right] / \kappa_{25}-\lambda_{0}}{T-25^{\circ} \mathrm{C}}$.

Necessary data for Eqs. (2) and (3) can be derived from measurements or from calculations.

In the remaining part of this manuscript, Eq. (1), complemented by Eq. (2) and Eq. (3), will be referenced as the RHO_LAMBDA approach.

In our RHO_LAMBDA approach, we use the Tanaka (2001) equation for pure water density, $\rho_{\mathrm{w}}$. If the composition of solutes in the water is known, the density of water is calculated by using RHOMV (Boehrer et al., 2010) and finally $\kappa_{25}$ is provided by the algorithm implemented in the PHREEQC code (Parkhust and Appelo, 1999), whose description can be found in Atkins and de Paula (2009) and on Appelo's webpage of PHREEQC (Appelo, 2016). This method (re-implemented in Python from the original code) calculates the specific conductance of a solution from the concentration, the activity coefficient and the diffusion coefficient of all the charged species. The diffusion coefficients can be found in Millero (2001).

\section{Rappbode Reservoir}

We demonstrate our density approach with the example of Rappbode Reservoir (Germany; for details on this reservoir, see Rinke et al., 2013, and references therein); its low electrical conductivity indicates low concentrations of solutes. From chemical analysis of a surface sample from 19 November 2010, we knew the major cations were calcium (13.8 $\left.\mathrm{mg} \mathrm{L}^{-1}\right)$ and sodium $\left(9.3 \mathrm{mg} \mathrm{L}^{-1}\right)$, while major anions were bicarbonate $\left(28.07 \mathrm{mg} \mathrm{L}^{-1}\right)$, sulfate $\left(18.5 \mathrm{mg} \mathrm{L}^{-1}\right)$ and chloride $\left(16.8 \mathrm{mg} \mathrm{L}^{-1}\right)$ (see Table 1$)$. In addition, considerable portions of organic matter $\left(3.1 \mathrm{mg} \mathrm{DOC} \mathrm{L}^{-1}\right)$ and silicate $\left(4.5 \mathrm{mg} \mathrm{L}^{-1}\right.$ of $\left.\mathrm{Si}(\mathrm{OH})_{4}\right)$ were contained in the sample. The procedure to apply the RHO_LAMBDA method in the case of Rappbode Reservoir can be summarized as follows.

1. For this sample, an electrical conductance $\kappa_{25}=$ $0.1635 \mathrm{mS} \mathrm{cm}^{-1}$ was calculated by inserting given concentrations into the PHREEQC algorithm (Parkhust and Appelo, 1999; Atkins and de Paula, 2009).
2. According to RHOMV, the density of this sample at $25^{\circ} \mathrm{C}$ was $\rho_{\mathrm{MV}}\left(T=25^{\circ} \mathrm{C}\right)=997.130 \mathrm{~kg} \mathrm{~m}^{-3}$ and $\rho_{\mathrm{W}}\left(T=25^{\circ} \mathrm{C}\right)=997.047 \mathrm{~kg} \mathrm{~m}^{-3}$.

3. Putting these numbers into Eq. (2) delivered $\lambda_{0}=$ $0.506 \mathrm{~kg} \mathrm{~cm} \mathrm{~m}^{-3} \mathrm{mS}^{-1}$.

4. Similarly, we evaluated $\lambda_{1}=-0.0012 \mathrm{~kg} \mathrm{~cm} \mathrm{~m}^{-3}$ $\mathrm{mS}^{-1} \mathrm{~K}^{-1}$ by putting $\rho_{\mathrm{w}}\left(T=5^{\circ} \mathrm{C}\right)=999.967 \mathrm{~kg} \mathrm{~m}^{-3}$ and $\rho_{\mathrm{MV}}\left(T=5{ }^{\circ} \mathrm{C}\right)=1000.053 \mathrm{~kg} \mathrm{~m}^{-3}$ into Eq. (3).

5. Finally, inserting the lambdas as coefficients into Eq. (1) delivered a density formula for Rappbode Reservoir.

\section{Assessments}

The practicability of this approach depends on its accuracy. This will first be assessed for Rappbode Reservoir water and its above-evaluated coefficients. However, for limnologists working on other limnic water bodies, an assessment of accuracy in the general range of limnic water composition is of fundamental interest. In conclusion, we chose a collection of lake waters of different chemical compositions and a wide range of concentrations. We included all lakes we knew of, where a reliable reference density could be provided and the chemical composition was known.

In particular, we included two further typical freshwater lakes, Lake Geneva and Lake Constance, which are well known in the limnological literature. As an example of saline lakes, we chose Mono Lake (e.g. Jellison et al., 1999). In order to include also water with a rather unusual composition, we chose two water samples from a meromictic open pit lake, the Waldsee, which contains large amounts of sulfate and dissolved iron (e.g. Dietz et al., 2008, 2012; Boehrer et al., 2009; von Rohden et al., 2010; Moreira et al., 2011). Finally, we used seawater, of which the composition is known at high accuracy, as a reference water for a standard comparison. Table 1 presents the original chemical compositions of the different lakes considered in the testing of the RHO_LAMBDA expression. Data were derived from chemical analysis (for experimental details, see Appendix A) or literature (for references, see Table 1). We complemented the set using synthetically produced lake water of differing compositions and concentrations from the work by Gomell and Boehrer (2015) in order to test systematically the influence of composition and concentration on the values of the coefficients $\lambda_{0}$ and $\lambda_{1}$ (for experimental details, see Appendix A).

For critical comparison with other density equations, this assessment section (Sect. 3) consists of two major parts: firstly we check the accuracy for different lakes and water samples and secondly we provide the lambda coefficients of several aquatic systems where we have direct measurements or a specifically obtained approach to density (e.g. Mono Lake or seawater) to check the accuracy of $\rho_{\lambda}$ in general. 

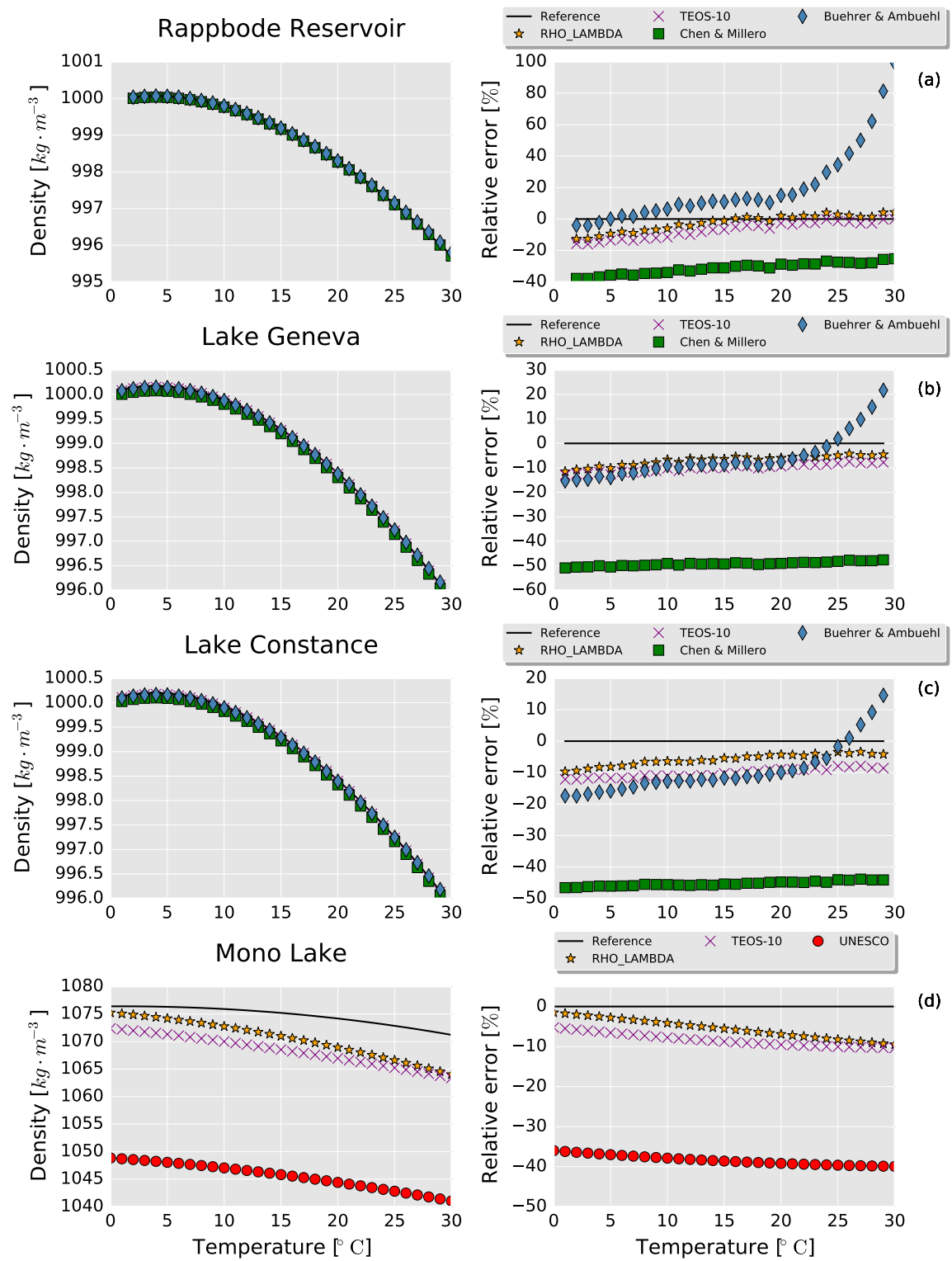

Figure 1.

Table 2 presents the results of the intermediate step calculations to obtain $\lambda_{0}$ and $\lambda_{1}$. As references for the assessment, we used the measured (for details, see Appendix A) or published data (Fig. 1a and b, Table 2).

The quantitative comparison between the different methods (including the method presented here, RHO_LAMBDA) and the reference values is shown in Fig. 1. Our approach mainly aimed at representing the density contribution of solutes. Hence, we related the difference to our reference with the contribution of the solutes

Rel.Error $=\left(\rho_{\lambda}-\rho_{\text {ref }}\right) /\left(\rho_{\text {ref }}-\rho_{\mathrm{w}}\right)$.

For temperatures in the range of $1-30^{\circ} \mathrm{C}$, usually found in typical limnic conditions, the values of the relative error de-

fined by Eq. (4) are displayed in the right column of Fig. 1. On purpose, we obtained the chemical composition from a different source (sample) than the density measurement. In this way, the variability of the water composition within one lake was included in the error determination in our assessment.

To judge the accuracy of our approach, we also inserted results from other formulas in common use for transferring CTD data into density: we included UNESCO (Fofonoff and Millard, 1983), TEOS-10 (IOC et al., 2010), Chen and Millero (1986) and Bührer and Ambühl (1975) (Fig. 1) as far as possible according to the defined range of applicability of the single formula. 

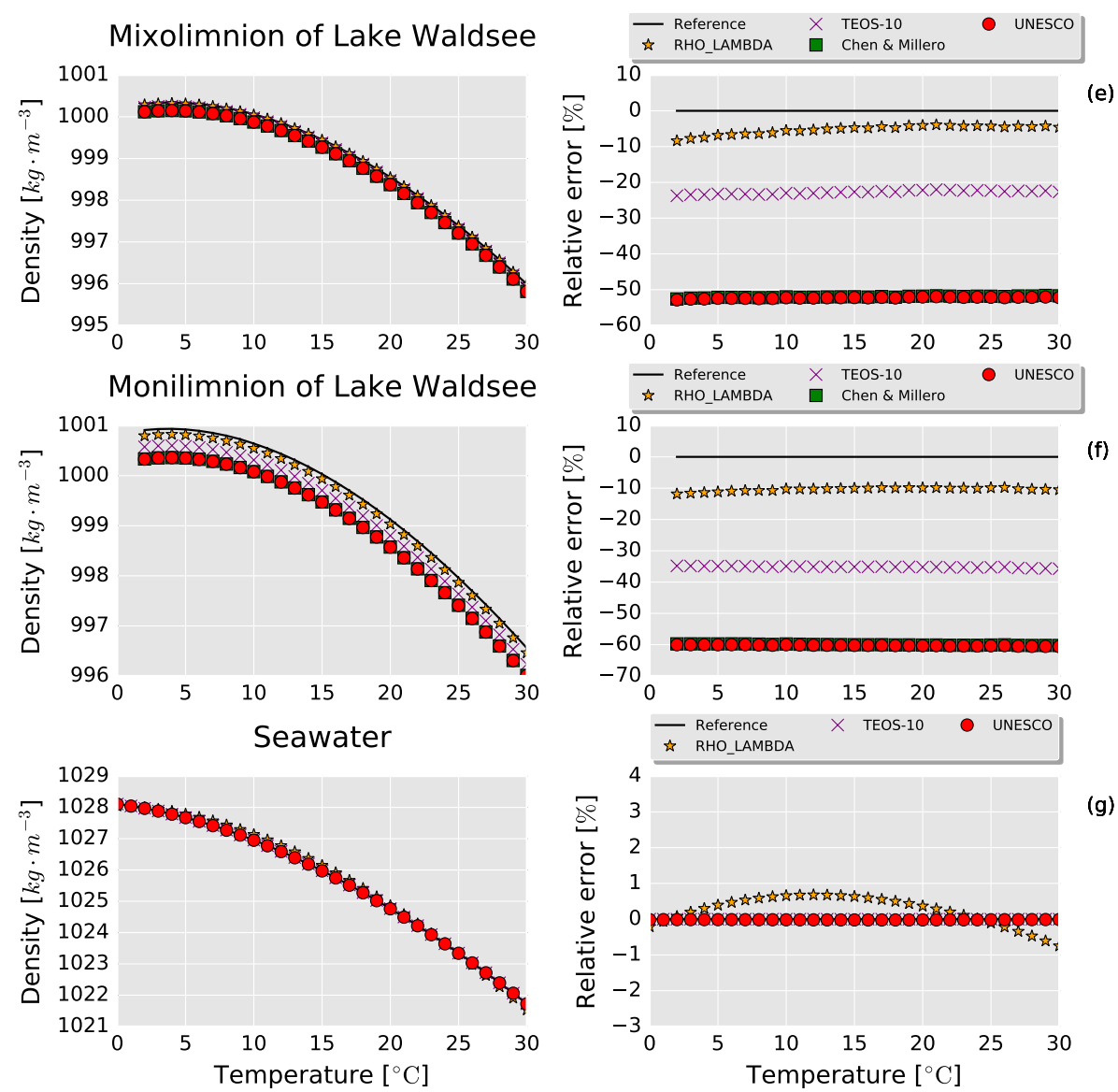

Figure 1. Test cases. The left panel presents the density curves of the different methods and the right panel shows the relative error of the density contribution of the solutes with respect to the reference. In all the cases, measured values have been used as a reference, except in the cases of Mono Lake (Jellison et al., 1999) and seawater (TEOS-10, IOC et al., 2010), which use specific density equations. (a) Rappbode Reservoir, (b) Lake Geneva, (c) Lake Constance, (d) Mono Lake. Continuation. (e) Mixolimnion of Waldsee, (f) Monimolimnion of Waldsee, (g) seawater.

Rappbode Reservoir. The measured conductance $\left(\kappa_{25}\right)$ of our Rappbode Reservoir sample was $0.1579 \mathrm{mS} \mathrm{cm}^{-1}$, which differed only by $4 \%$ from the value $0.1635 \mathrm{mS} \mathrm{cm}^{-1}$ calculated using the PHREEQC electrical conductivity algorithm at $25^{\circ} \mathrm{C}$ (described in Atkins and De Paula, 2009). This is within the measurement accuracy of the chemical analysis. Reference density was produced by measuring in a PAAR DSA 5000 densitometer from 1 to $30^{\circ} \mathrm{C}$.

We can see that the RHO_LAMBDA method reproduced the reference values of the water sample from Rappbode Reservoir with a relative error ranging from -12.7 to $4.3 \%$. The deviation from the reference was lower than $5 \%$ in the range 10 to $27^{\circ} \mathrm{C}$. Among the other compared approaches, TEOS-10 showed the best results, with relative error ranging from -15.7 to $0.1 \%$. The Bührer and Ambühl (1975) approach resulted in a relative error ranging from -4.0 to $99.3 \%$ and strongly rising with temperatures increasing above $20^{\circ} \mathrm{C}$. Results according to Chen and Millero (1986) ranged between -37.8 and $-25.3 \%$.
Lake Geneva. Calculated and measured electrical conductivity $\left(\kappa_{25}\right)$ of a water sample from 7 November 2013 differed by less than $1 \%$ for $25^{\circ} \mathrm{C}$ (Table 2). Reference density was produced from this sample in a PAAR DSA 5000 densitometer. The relative error ranged from -11.5 to $-4.6 \%$ for our RHO_LAMBDA approach. Bührer and Ambühl (1975) (relative error -15.3 to $21.7 \%$ ), TEOS-10 (relative error -12.9 to $-7.8 \%$ ) and Chen and Millero (1986) (relative error -50.9 to $-47.6 \%$ ) showed larger deviations from the reference.

Lake Constance. The composition shown in Table 1 mainly coincided with the analysis done by Stabel (1998). The calculated conductivity at $25^{\circ} \mathrm{C}\left(\kappa_{25}\right)$ of $0.330 \mathrm{mS} \mathrm{cm}^{-1}$ differed from the measured value of $0.322 \mathrm{mS} \mathrm{cm}^{-1}$ by $3 \%$. The reference density was again from measurements in a PAAR DSA 5000 densitometer. The relative error ranged from -9.7 to $-4.2 \%$ for the RHO_LAMBDA approach. TEOS-10 (relative error -12.2 to $-8.6 \%$ ), Bührer and Ambühl (1975) (relative error -17.4 to $14.6 \%$ ) and Chen and 
Table 1. Original chemical composition of the water in different test cases presented in Sect. 3. All values except $\mathrm{pH}^{\text {are }} \mathrm{presented} \mathrm{in} \mathrm{mg} \mathrm{L}^{-1}$ (NA - not analysed).

\begin{tabular}{|c|c|c|c|c|c|c|c|}
\hline & $\begin{array}{l}\text { Reservoir } \\
\text { Rappbode }\end{array}$ & $\begin{array}{r}\text { Lake } \\
\text { Geneva }\end{array}$ & $\begin{array}{r}\text { Lake } \\
\text { Constance }\end{array}$ & $\begin{array}{r}\text { Mono } \\
\text { Lake }\end{array}$ & $\begin{array}{r}\text { Waldsee } \\
\text { (mixo.) }\end{array}$ & $\begin{array}{r}\text { Waldsee } \\
\text { (monimo.) }\end{array}$ & Seawater \\
\hline $\mathrm{pH}$ & 7.14 & 7.0 & 7.9 & 9.8. & 7.1 & 6.7 & 7.0 \\
\hline $\mathrm{K}^{+}$ & 1.00 & 1.74 & 1.48 & 1610.92 & 7.04 & 10.17 & 404.23 \\
\hline $\mathrm{Ca}^{2+}$ & 13.8 & 44.30 & 51.2 & 6.01 & 61.32 & 89.78 & 417.38 \\
\hline $\mathrm{Mg}^{2+}$ & 3.30 & 6.49 & 9.03 & 31.59 & 12.88 & 17.50 & 1299.88 \\
\hline $\mathrm{Fe}^{2+}$ & 0.00 & NA & NA & NA & 0.22 & 117.83 & NA \\
\hline $\mathrm{Fe}^{3+}$ & NA & NA & NA & NA & 0.28 & 13.96 & NA \\
\hline $\mathrm{Mn}^{2+}$ & 0.004 & $<0.010$ & $<0.007$ & NA & 0.22 & 0.88 & NA \\
\hline $\mathrm{Al}^{3+}$ & 0.01 & $<0.005$ & $<0.02$ & NA & NA & NA & NA \\
\hline $\mathrm{F}^{-}$ & 0.00 & NA & NA & NA & NA & NA & 1.31 \\
\hline $\mathrm{HCO}_{3}^{-}$ & 28.07 & 94.58 & 136.68 & 3276.67 & 57.97 & 374.04 & 106.15 \\
\hline $\mathrm{CO}_{3}^{2-}$ & NA & 0.000 & NA & 17726.95 & 0.00 & 0.00 & 14.53 \\
\hline $\mathrm{Si}(\mathrm{OH})_{4}$ & 4.50 & 0.582 & 4.42 & NA & NA & NA & NA \\
\hline $\mathrm{B}(\mathrm{OH})_{4}^{-}$ & NA & NA & NA & 752.45 & NA & NA & 4.23 \\
\hline $\begin{array}{l}\text { DOC density } \\
\text { correction } \\
\left(\mathrm{kg} \mathrm{m}^{-3}\right)^{*}\end{array}$ & 0.0 & 0.0 & 0.0 & 0.0 & 0.015 & 0.060 & 0.0 \\
\hline Correction** & $0 \%$ & $-16 \%$ & $10.4 \%$ & $15 \%$ & $7 \%$ & $-15 \%$ & $0 \%$ \\
\hline $\begin{array}{l}\text { Data } \\
\text { sources }\end{array}$ & Measured & Measured & Measured & Jellison et al. (1999) & Dietz et al. (2008) & $\begin{array}{r}\text { Millero et al. (2008) } \\
\text { Dietz et al. (2012) }\end{array}$ & \\
\hline
\end{tabular}

* Density modified by addition of this quantity expressed in $\mathrm{kg} \mathrm{m}^{-3}$

* Correction of cation concentrations for charge balance

Millero (1986) (relative error -46.6 to $-44.1 \%$ ) again had larger deviations from the reference. The strong increase in the relative error of Bührer and Anbühl (1975) with temperature was smallest for Lake Constance compared to the other freshwater lakes.

Mono Lake. We evaluated density for a water sample of conductivity $\kappa_{25}=85.67 \mathrm{mS} \mathrm{cm}^{-1}$ which was provided by Jellison et al. (1999) and which differed by $12 \%$ from the calculated value $96.61 \mathrm{mS} \mathrm{cm}^{-1}$ using the PHREEQC algorithm. The density formula by Jellison et al. (1999) was used as the reference density. In this case, the relative error using RHO_LAMBDA ranged from -9.5 to $-1.5 \%$ even in this lake with such saline waters and unusual composition. Also in this case, TEOS-10 showed larger deviation from the reference (relative error -10.4 to $-5.2 \%$ ). The largest relative error was found for the UNESCO equation according to Foffonof and Millard (1983) (relative error -39.9 to $-36.0 \%$ ).

Waldsee mixolimnion/Waldsee monimolimnion. This case presented a meromictic open pit lake (Boehrer et al., 2008; Dietz et al., 2008, 2012; von Rohden et al., 2010; Moreira et al., 2011) of moderate salinity $(0.22 \mathrm{psu}$ in the mixolimnion and $0.6 \mathrm{psu}$ in the monimolimnion, Moreira et al., 2011), but its composition differed from the usual carbonate or chloride waters. Composition was obtained from Dietz et al. (2008, 2012). The DOC (dissolved organic carbon) contribution was added according to Dietz et al. (2012). This correction increased density by $0.015 \mathrm{~kg} \mathrm{~m}^{-3}$ in the mixolimnion and by $0.06 \mathrm{~kg} \mathrm{~m}^{-3}$ in the monimolimnion.

The calculated $\kappa_{25}$ differed by $7.0 \%$ from the reference value in the mixolimnion and by $7.6 \%$ in the monimolimnion (Table 2). This was the highest difference between reference and calculated values of all waters considered in this study. Probably, the very special chemical composition of the waters was the reason. The missing data for ammonia and silicate may also have contributed, in particular in the monimolimnion. Measurements in the work of Boehrer et al. (2009) were used as a density reference.

The relative error of the RHO_LAMBDA approach ranged from -8.4 to $-3.9 \%$ in the mixolimnion. In the monimolimnion, the relative error ranged from -11.9 to $-9.8 \%$ for the RHO_LAMBDA approach. The deviation from the reference was substantially larger for all other compared ap- 
Table 2. Summary of the calculated values for obtaining RHOMV_LAMBDA coefficients. Lambdas and references: $\lambda_{0}$ and $\lambda_{1}$ represent the lambda values obtained using the chemical composition of Table 1 to calculate density and conductivity at 5 and $25^{\circ} \mathrm{C}$, while $\lambda_{0}^{*}$ and $\lambda_{1}^{*}$ represent the lambda values obtained from a linear regression of the density reference. $\lambda_{0}$ and $\lambda_{0}^{*}$ are expressed in $\mathrm{kg} \mathrm{cm} \mathrm{m}^{-3} \mathrm{mS}^{-1}$ and $\lambda_{1}$ and $\lambda_{1}^{*}$ are expressed in $\mathrm{kg} \mathrm{cm} \mathrm{m}^{-3} \mathrm{mS}^{-1} \mathrm{~K}^{-1}$. Density values are expressed in $\mathrm{kg} \mathrm{m}^{-3}$. Corrected salinity shows the values of Practical salinity corrected by a factor of 1.00488 for the Chen and Millero (1986) method. For more details, see text.

\begin{tabular}{|c|c|c|c|c|c|c|c|}
\hline & $\begin{array}{l}\text { Reservoir } \\
\text { Rappbode }\end{array}$ & $\begin{array}{r}\text { Lake } \\
\text { Geneva }\end{array}$ & $\begin{array}{r}\text { Lake } \\
\text { Constance }\end{array}$ & $\begin{array}{l}\text { Mono } \\
\text { Lake }\end{array}$ & $\begin{array}{r}\text { Waldsee } \\
\text { (mixo.) }\end{array}$ & $\begin{array}{r}\text { Waldsee } \\
\text { (monimo.) }\end{array}$ & Seawater \\
\hline $\begin{array}{l}\kappa_{20} \\
(\text { measured) } \\
\left(\mu \mathrm{cm}^{-1}\right)\end{array}$ & 142.0 & 263 & 302 & NA & NA & NA & NA \\
\hline $\begin{array}{l}\kappa_{25} \\
(\text { measured) } \\
\left(\mu \mathrm{cm}^{-1}\right)\end{array}$ & 157.9 & 294 & 333.7 & 85668 & 550 & 1050 & 53064.9 \\
\hline $\begin{array}{l}\kappa_{25}(\text { calc. }) \\
\left(\mu \mathrm{s} \mathrm{cm} \mathrm{cm}^{-1}\right)\end{array}$ & 163.49 & 296.81 & 329.77 & 96609.50 & 588.50 & 969.93 & 53762.53 \\
\hline $\begin{array}{l}\text { Practical } \\
\text { salinity }\end{array}$ & 0.0770 & 0.127 & 0.1613 & 83.04 & 0.220 & 0.60 & 35.00 \\
\hline $\begin{array}{l}\text { Absolute } \\
\text { salinity }\end{array}$ & 0.0997 & 0.22 & 0.251 & 91.11 & 0.351 & 0.78 & 35.165 \\
\hline $\begin{array}{l}\text { Corrected } \\
\text { salinity }\end{array}$ & 0.0774 & 0.128 & 0.1621 & 83.45 & 0.221 & 0.6029 & 35.171 \\
\hline $\begin{array}{l}\rho_{\mathrm{MV}} \\
\left(T=25^{\circ} \mathrm{C}\right)\end{array}$ & 997.130 & 997.222 & 997.252 & 1075.480 & 997.383 & 997.744 & 1023.662 \\
\hline $\begin{array}{l}\rho_{\mathrm{MV}} \\
\left(T=5{ }^{\circ} \mathrm{C}\right)\end{array}$ & 1000.053 & 1000.149 & 1000.181 & 1083.661 & 1000.316 & 1000.691 & 1028.150 \\
\hline $\begin{array}{l}\rho_{\text {ref }} \\
\left(T=25^{\circ} \mathrm{C}\right)\end{array}$ & 997.126 & 997.228 & 997.253 & 1069.936 & 997.391 & 997.958 & 1023.344 \\
\hline $\begin{array}{l}\rho_{\text {ref }} \\
\left(T=5^{\circ} \mathrm{C}\right)\end{array}$ & 1000.059 & 1000.168 & 1000.194 & 1075.447 & 1000.332 & 1000.923 & 1027.600 \\
\hline Data sources & Measured & Measured & Measured & Jellison et al. (1999) & Dietz et al. (2008) & $\begin{array}{r}\text { Millero et al. (2008) } \\
\text { Dietz et al. (2012) } \\
\text { von Rohden et al. (2010) } \\
\text { Moreira et al.(2011) }\end{array}$ & \\
\hline$\lambda_{0}$ & 0.51 & 0.59 & 0.62 & 0.81 & 0.60 & 0.78 & 0.50 \\
\hline$\lambda_{1}$ & -0.0012 & -0.0013 & -0.0014 & -0.0027 & -0.0011 & -0.0014 & -0.0015 \\
\hline$\lambda_{0}^{*}$ & 0.50 & 0.62 & 0.64 & 0.85 & 0.63 & 0.87 & 0.50 \\
\hline$\lambda_{1}^{*}$ & -0.0042 & -0.0034 & -0.0033 & -0.0015 & -0.0020 & -0.0022 & -0.0013 \\
\hline A.E. ${ }^{1}$ & $4.3 \%$ & $6.9 \%$ & $5.9 \%$ & $5.5 \%$ & $5.2 \%$ & $10.4 \%$ & $0.4 \%$ \\
\hline M.E. ${ }^{2}$ & $12.7 \%$ & $11.5 \%$ & $9.7 \%$ & $9.5 \%$ & $8.4 \%$ & $11.85 \%$ & $0.75 \%$ \\
\hline
\end{tabular}

1 Average absolute value of relative error.

2 Max. absolute value of relative error.

proaches (Fig. 1a and b). The averages of the absolute values of the relative error were $22.8,52.0$ and $52.3 \%$ for TEOS-10 (IOC et al., 2010), Chen and Millero (1986) and UNESCO (Foffonof and Millard, 1983) in the mixolimnion, respectively. In the monimolimnion, the values were $35.2 \%$ for TEOS-10, 60.0\% for Chen and Millero (1986) and $60.2 \%$ for UNESCO (Foffonof and Millard, 1983).

Seawater. The seawater composition was obtained from Millero et al. (2008) and we used TEOS-10 (IOC et al., 2010) as our seawater density reference. Electrical conductivity was calculated for this composition and resulted in $53.76 \mathrm{mS} \mathrm{cm}^{-1}$, while the reference value given by Millero et al. (2008) was $53.06 \mathrm{mS} \mathrm{cm}^{-1}$. That meant the deviation was $1.3 \%$. As expected - both formulas were specifically de- signed for ocean water -, the relative error of the UNESCO approach according to Foffonof and Millard (1983) was very small, ranging between -0.02 and $-0.01 \%$. This was probably a result of numerical uncertainties of the calculations. The relative error of our RHO_LAMBDA approach ranged between -0.75 and $0.68 \%$.

\section{Discussion}

In all cases, our density approach reproduced the density contribution of the salts to within $10 \%$. This is better than most of the other approaches, which differed by up to $60 \%$ from the correct values. Even in the case of very low concentrations (Rappbode Reservoir) and very high concentrations 
(Mono Lake) as well as in very special water composition (mine lake Waldsee), the $10 \%$ accuracy for the salt contribution was achieved with our RHO_LAMBDA approach. The observed strong increase in the relative error with temperature for Bührer and Ambühl (1975) was caused by its validity limited to $24^{\circ} \mathrm{C}$. Spatial and temporal variability of solute composition could contribute to errors in density calculation. However, where we attained chemical composition separately (i.e. from another sample) from the density information, this error is intrinsically included in our assessment and hence in the value that we supply for the RHO_LAMBDA approach.

The first coefficient $\lambda_{0}$ varied by more than a factor of 2 between 0.37 and $0.88 \mathrm{~kg} \mathrm{~cm} \mathrm{~m}^{-3} \mathrm{mS}^{-1}$; see Fig. 2. This explained that a density formula with constant coefficients could never be able to mimic density accurately for a larger range of lake waters. Obviously the coefficient $\lambda_{0}$ depended on the composition of the solutes. A dominance of doublecharged ions - as opposed to single-charged ions - led to higher values of $\lambda_{0}$. This effect was clearly visible in the inclusion of calculated values for a $\mathrm{NaCl}$ solution of $1 \mathrm{~g} \mathrm{~L}^{-1}$ and a $\mathrm{CaSO}_{4}$ solution of $1 \mathrm{~g} \mathrm{~L}^{-1}$ (Fig. 2).

Also, the concentration of solutes had a decisive effect on the coefficients. We used density measurements of a dilution series of synthetic lake waters by Gomell and Boehrer (2015) of 1, 3, 10,30, or $90 \mathrm{~g} \mathrm{~L}^{-1}$ of a mixture of $\mathrm{KCl}, \mathrm{NaHCO}_{3}$, and $\mathrm{Na}_{2} \mathrm{SO}_{4}$. We included lambda coefficients from RHO_LAMBDA approach "Mix" together with regressions of published measured data "Mix-M" (Fig. 2). Both empirical data as well as RHO_LAMBDA results reflected the concentration effect on $\lambda_{0}$ of a factor of 1.5. Although not perfect, the agreement between empirical data and RHO_LAMBDA values lay within the $10 \%$ margin we found for lake waters above.

Values for $\lambda_{1}$ nearly all lay between -0.001 and $-0.002 \mathrm{~kg} \mathrm{~cm} \mathrm{~m}^{-3} \mathrm{mS}^{-1} \mathrm{~K}^{-1}$. Hence, the $\lambda_{1}$ term delivered a small contribution in all cases, i.e. always an order of magnitude smaller compared to the $\lambda_{0}$ term. As a consequence, it could be neglected for most limnological applications. Though not really necessary for an absolute density calculation, $\lambda_{1}$ was included to also represent the shift of temperature of maximum density for a given lake water composition, which could not be achieved with the $\lambda_{0}$ term alone. Negative values of $\lambda_{1}$ indicated a shift of the temperature of maximum density to lower temperatures. A closer look at the $\lambda_{1}$ values revealed that some empirical values (also the Mono Lake reference derived from empirical measurements) were considerably lower than expected from coefficients of physical chemistry. However, the difference posed the question of how accurately the shift of temperature of maximum density would actually be indicated by coefficients of the physical chemistry literature. The largest discrepancies appeared for freshwater lakes (Rappbode Reservoir, Lake Geneva, Lake Constance) where the shift is small.

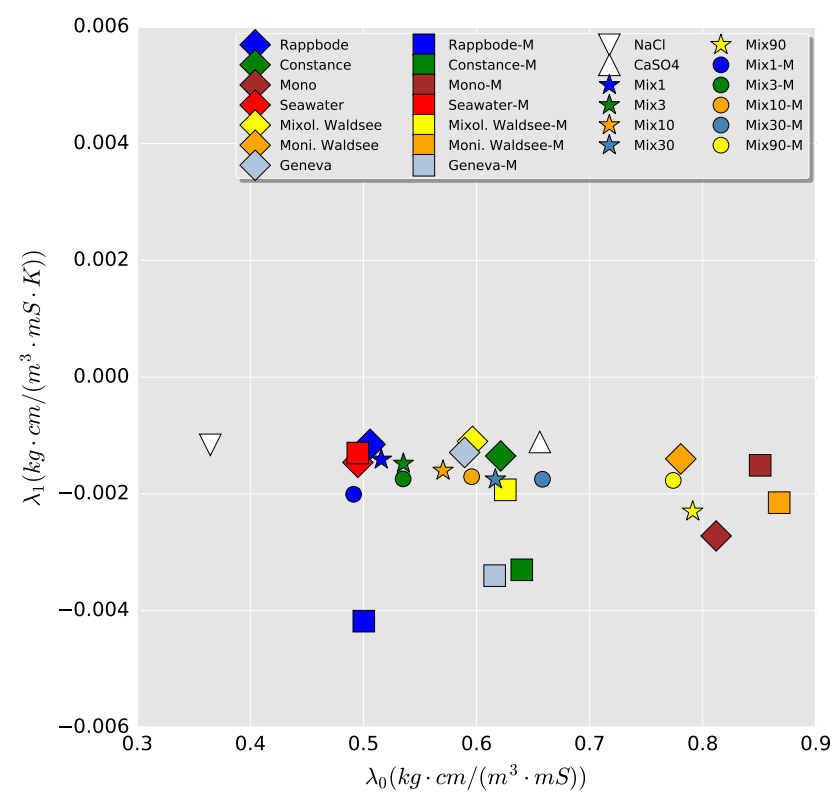

Figure 2. Distribution of the values of $\lambda_{1}$ vs. $\lambda_{0}$. Concentrations for $\mathrm{NaCl}$ and $\mathrm{CaSO}_{4}$ are $1 \mathrm{~g} \mathrm{~L}^{-1}$ in both cases. Chemical compositions for the lakes and seawater are presented in Table 1. The water samples labelled as "Mix" are proportional mixtures of $\mathrm{KCl}, \mathrm{NaHCO}_{3}$, and $\mathrm{Na}_{2} \mathrm{SO}_{4}$ of $1,3,10,30$ and $90 \mathrm{~g} \mathrm{~L}^{-1}$ (Gomell and Boehrer, 2015) and the water samples labelled as "-M" correspond to the lambda coefficients obtained from direct measurements of density and conductivity.

The values of $\lambda_{0}$ and $\lambda_{1}$ have also been calculated using direct measurements of density (starred values $\lambda_{0}^{*}$ and $\lambda_{1}^{*}$ ). In the case of $\lambda_{0}$ only slight differences can be found between the values calculated from chemical composition and from direct measurements of density. However, those differences increase in the case of $\lambda_{1}$, as mentioned above.

\section{Conclusions}

We showed that the correlation between electrical conductivity and density depends strongly on the composition and concentration of solutes. As a consequence, the limnic range cannot be covered with one formula with constant coefficients. However, a simple mathematical addition of two terms to a pure water formula is able to represent the density contribution of solutes in all our examples with an error of less than $10 \%$. This is sufficient for most limnological applications and is better than any other density approach based on CTD data, if not specifically designed for a given lake water.

Only two coefficients $\lambda_{0}$ and $\lambda_{1}$ need to be evaluated: while $\lambda_{0}$ varies considerably between lakes, the numerical evaluation of $\lambda_{1}$ delivers very similar values of $\lambda_{1} \sim$ $-0.0015 \mathrm{~kg} \mathrm{~cm} \mathrm{~m}^{-3} \mathrm{mS}^{-1} \mathrm{~K}^{-1}$ for any lake water composition. Hence, once $\lambda_{0}$ has been evaluated for a lake, a rather 
accurate and simple density formula can be used for CTD data. The approach uses conductance $\kappa_{25}$, which can be measured in limnic waters, and thus avoids salinity, which is badly defined for limnic waters and, hence, is a precarious quantity. The inclusion of this simple and more accurate approach for potential density calculation in numerical lake models is therefore recommended.

For convenient use and implementation, a density calculator tool is provided at https://sourceforge.net/projects/ densitycalc.

\section{Data availability}

Webax-Web access to numerical tools of limnology is available at http://www.ufz.de/webax. TEOS-10 original Fortran 90 library and related tools are available at http://www. teos-10.org/software.htm. Density calculator is available at https://sourceforge.net/projects/densitycalc. All the data used in this manuscript to calculate the lambda coefficients and density values are provided in Tables 1 and 2 . 


\section{Appendix A: Measurement of samples taken for this study}

All samples were taken as surface samples and stored cooled and without bubbles in polyethylene bottles until measurements and analysis in the lab.

Density measurements were done in $1{ }^{\circ} \mathrm{C}$ steps between 1 and $30^{\circ} \mathrm{C}$ using a PAAR DSA500 densitometer. Measurements of electrical conductivity were done with a MultiLabPilot conductivity meter (WTW, Germany).

$\mathrm{pH}$ was measured using a HQ11d pH meter (Hach-Lange, Germany) in the lab. Sulfate $\left(\mathrm{SO}_{4}^{2-}\right)$ and chloride $\left(\mathrm{Cl}^{-}\right)$were analysed by suppressed conductivity using an ICS-3000 ion chromatography system (Dionex, Idstein, Germany) and automatically generated potassium hydroxide eluent. Concentrations of $\mathrm{Ca}, \mathrm{Mg}, \mathrm{Na}, \mathrm{K}, \mathrm{Al}, \mathrm{Fe}$, and $\mathrm{Mn}$ were determined by optical emission spectroscopy with inductively coupled plasma (ICP-OES, Perkin-Elmer, OPTIMA 3000, Germany) (Baborowski, et al., 2011). Acidity and alkalinity were measured by an automatic titrator (Metrohm, Germany). Bicarbonate and carbonate were calculated based on acidity, alkalinity and $\mathrm{pH}$ using PHREEQC (Parkhust and Appelo, 1999).

Nitrate $\left(\mathrm{NO}_{3}^{-}\right)$(DIN_EN_ISO_13395, 1996; Herzsprung, et al., 2005), ammonium $\left(\mathrm{NH}_{4}^{+}\right)$(Krom, 1980; DIN_EN_ISO_11732, 1997), and silicate $\left(\mathrm{Si}(\mathrm{OH})_{4}\right)$ (Smith and Milne, 1981) were measured by continuous flow analysis (CFA, Skalar, the Netherlands) (Herzsprung et al., 2006).

Fluoride $\left(\mathrm{F}^{-}\right)$and borate $\left(\mathrm{B}(\mathrm{OH})_{4}^{-}\right)$were not included into the analyses because they usually are not relevant for density in typical freshwater lakes.

\section{A1 Corrections of original chemical analyses for charge balance}

If the charge balance between cations and anions was higher than $5 \%$ or below $-5 \%$, the concentrations of cations were increased or diminished to reach balance by keeping the ratios of the cations to each other constant. The following corrections were necessary: reduction by $16 \%$ for Lake Geneva, reduction by $10.4 \%$ for Lake Constance, increase by $15 \%$ for Mono Lake, increase by $7 \%$ for mixolimnion, and reduction by $15 \%$ for monimolimnion of the Waldsee.

\section{A2 Application of the TEOS10 algorithm in the assessment}

The initial algorithm of TEOS10 according to IOC et al. (2010) was applied only for seawater serving as a reference. In all other cases, the adaptation for limnic systems proposed by Pawlowicz and Feistel (2012) was used since all other systems are limnic. Because the only difference between both algorithms is the calculation of the so-called absolute salinity and the equation for density is the same, "TEOS-" was used in the legends of all diagrams in Fig. 1a and $\mathrm{b}$.

\section{A3 Preparation of synthetic solutions}

For systematic investigation of dependencies of coefficients, $\lambda_{0}$ and $\lambda_{1}$ we prepared solutions of pure $\mathrm{NaCl}\left(1 \mathrm{~g} \mathrm{~L}^{-1}\right)$ and pure $\mathrm{CaSO}_{4}\left(1 \mathrm{~g} \mathrm{~L}^{-1}\right)$ and proportional mixtures of $\mathrm{KCl}$, $\mathrm{NaHCO}_{3}$ and $\mathrm{Na}_{2} \mathrm{SO}_{4}$ having overall concentrations of 1,3 , 10,30 and $90 \mathrm{~g} \mathrm{~L}^{-1}$. The water samples are labelled using the chemical formula of the salts $\left(\mathrm{NaCl} ; \mathrm{CaSO}_{4}\right)$ and as "MixN" with $\mathrm{N}$ being a number indicating the concentration. More details about these prepared solutions can be found in Gomell and Boehrer (2015).

\section{A4 Software}

All the density methods have been implemented in Python 2.7 except the TEOS-10 (IOC et al., 2010). For TEOS-10 the original Fortran 90 library has been downloaded from http: //www.teos-10.org/software.htm and compiled using f2py. The generated Python library has been used directly for the calculations using the Python 2.7 scripts. All the results presented in this manuscript can be obtained using the "density calculator" provided at https://sourceforge.net/projects/ densitycalc. 
Acknowledgements. We thank Ulrich Lemmin for taking and sending a water sample from Lake Geneva, and Karsten Rinke for a water sample from Lake Constance.

The article processing charges for this open-access publication were covered by a Research

Centre of the Helmholtz Association.

Edited by: M. Hipsey

Reviewed by: three anonymous referees

\section{References}

Appelo, C. A. J.: Specific Conductance: how to calculate, to use, and the pitfalls, available at: http://www.hydrochemistry.eu/ exmpls/sc.html, last access: June 2016.

Atkins, P. and de Paula, A.: Physical Chemistry, 9th ed, Oxford University Press, 2009.

Baborowski, M., Büttner, O., and Einax, J. W.: Assessment of Water Quality in the Elbe River at Low Water Conditions Based on Factor Analysis, Clean - Soil, Air, Water, 39, 437-443, doi:10.1002/clen.201000373, 2011.

Boehrer, B.: WEBAX - Web access to numerical tools of limnology, available at: http://www.ufz.de/webax (last access: July 2016), 2010.

Boehrer, B. and Schultze, M.: Stratification of lakes, Rev. Geophys., 46, RG2005, doi:10.1029/2006RG000210, 2008.

Boehrer, B., Dietz S., von Rohden, C., Kiwel, U., Jöhnk, K., Naujoks, S., Ilmberger, J., and Lessmann, D.: Double-diffusive deep water circulation in an iron-meromictic lake, Geochem. Geophy. Geosy., 10, Q06006, doi:10.1029/2009GC002389, 2009.

Boehrer, B., Herzsprung, P., Schultze, M., and Millero, F. J.: Calculating density of water in geochemical lake stratification models, Limnol. Oceanogr-Meth., 8, 567-574, doi:10.4319/lom.2010.8.0567, 2010.

Bührer, H. and Ambühl, H.: Die Einleitung von gereinigtem Abwasser in Seen, Schweizerische Zeitschrift für Hydrologie, 37, 347-369, doi:10.1007/BF02503411, 1975.

Burchard, H., Bolding, K., and Villarreal, M. R.: GOTM - a general ocean turbulence model. Theory, applications and test cases, Tech. Rep. EUR 18745 EN, European Commission, 1999.

Chen, C.-T. A. and Millero, F. J.: Precise thermodynamic properties for natural waters covering only the limnological range, Limnol. Oceanogr., 31, 657-662, 1986.

Cole, T. M. and Buchak, E. M.: CE-QUAL-W2: A TwoDimensional, Laterally Averaged, Hydrodynamic and Water Quality Model Version 2.0, US Army Corps of Engineers, Waterways Experiment Station, 1995.

Dietz, S., Seebach, A., Jöhnk, K. D., Boehrer, B., Knoller, K., and Lessmann, D.: Meromixis in mining lake Waldsee, Germany: hydrological and geochemical aspects of stratification, Verh. Int. Verein. Limnol., 30, 485-488, 2008.

Dietz, S., Lessmann, D., and Boehrer, B.: Contribution of Solutes to Density Stratification in a Meromictic Lake (Waldsee/Germany), Mine Water Environ., 31, 129-137, doi:10.1007/s10230-0120179-3, 2012.

DIN_EN_ISO_11732: Water quality - Determination of ammonium nitrogen - Method by flow analysis (CFA and FIA) and spectrometric detection (ISO 11732:2005); German version EN ISO 11732:2005, Beuth Verlag, 1997.

DIN_EN_ISO_13395: Water quality - Determination of nitrite nitrogen and nitrate nitrogen and the sum of both by flow analysis (CFA and FIA) and spectrometric detection (ISO 13395:1996); German version EN ISO 13395:1996, Beuth Verlag, 1996.

Fofonoff, N. P. and Millard Jr., R. C.: Algorithms for communication of fundamental properties of seawater, UNESCO technical papers in marine science, 44, 1983.

Gal, G., Hipsey, M. R., Parparov, A., Wagner, U., Makler, V., and Zohary, T.: Implementation of ecological modeling as an effective management and investigation tool: lake Kinneret as a case study, Ecol. Model., 220, 1697-1718, doi:10.1016/j.ecolmodel.2009.04.010, 2009.

Gomell, A. and Boehrer, B.: Accuracy of lake water density calculated from molar volumes: RHOMW, submitted, 2015.

Herzsprung, P., Duffek, A., Friese, K., de Rechter, M., Schultze, M., and von Tuempling, W.: Modification of a continuous flow method for analysis of trace amounts of nitrate in iron-rich sediment pore-waters of mine pit lakes, Water Res., 39, 1887-1895, doi:10.1016/j.watres.2005.02.017, 2005.

Herzsprung, P., Bozau, E., Büttner, O., Duffek, A., Friese, K., Koschorreck, M., Schultze, M., von Tümpling, W., and WendtPotthoff, K.: Routine analysis of sediment pore water of high ionic strength, Acta Hydroch. Hydrob., 34, 593-607, doi:10.1002/aheh.200500656, 2006.

Hodges, B. and Dallimore, C.: Estuary, lake and coastal ocean model: ELCOM, v3.0 user manual, Centre for Water Research, Univ. Western Australia (last access: 12 March 2014), 2007.

Imberger, J. and Patterson, J. C.: A dynamic reservoir simulation model -DYRESM: 5, in: Transport models for inland and coastal waters, edited by: Fischer, H., Academic Press, New York, 310 361, 1981

Imboden, D. M. and Wüest, A.: Mixing mechanisms in lakes, in: Physics and chemistry of lakes, edited by: Lerman, A., Imboden, D. M., and Gat, J. R., Springer, Berlin, 83-138, 1995.

IOC, SCOR, and IAPSO: The international thermodynamic equation of seawater - 2010: Calculation and use of thermodynamic properties, Manual and Guides No. 56. Intergovernmental Oceanographic Commission, UNESCO (English), available at: http://www.TEOS-10.org (last access: July 2016), 2010.

Jellison, R., Macintyre, S., and Millero, F. J.: Density and conductivity properties of $\mathrm{Na}-\mathrm{CO}_{3}-\mathrm{Cl}-\mathrm{SO}_{4}$ from Mono Lake, California, USA, International J. Salt Lake Res., 8, 41-53, doi:10.1007/BF02442136, 1999.

Karakas, G., Brookland, I., and Boehrer, B.: Physical characteristics of Acidic Mining Lake 111, Aquat. Sci., 65, 297-307, doi:10.1007/s00027-003-0651-z, 2003.

Katsev, S., Crowe, S. A., Mucci, A., Sundby, B., Nomosatyo, S., Haffner, G. D., and Fowle, D. A.: Mixing and its effects on biogeochemistry in the persistently stratified, deep, tropical, Lake Matano, Indonesia, Limnol. Oceanogr., 55, 763-776, 2010.

Kell, G. S.: Density, thermal expansivity, and compressibility of liquid water from $0^{\circ}$ to $150^{\circ} \mathrm{C}$ : correlations and tables for atmospheric pressure and saturation reviewed and expressed on 1968 temperature scale, J. Chem. Eng. Data, 20, 97-105, doi:10.1021/je60064a005, 1975.

Krom, M.: Spectrophotometric determination of ammonia; a study of modified Berthelot reaction using salicylate and dichloroiso- 
cyanurate, Analyst, 109, 305-316, doi:10.1039/AN9800500305, 1980.

McDougall, T. J. and Barker, P. M.: Getting started with TEOS10 and the Gibbs Seawater (GSW) Oceanographic Toolbox, 28 pp., SCOR/IAPSO WG127, ISBN 978-0-646-55621-5, available at: http://www.teos-10.org/software.htm (last access: July 2016), 2011.

Millero, F. J.: Physical Chemistry of Natural Waters; WileyInterscience, New York, 2001.

Millero, F. J., Feistel, R., Wright, D. G., and McDougall, T. J.: The composition of Standard Seawater and the definition of the Reference-Composition Salinity Scale, Deep Sea Res. Pt. I, 55, 50-72, doi:10.1016/j.dsr.2007.10.001, 2008.

Moreira, S.: Density Calculator - A water density calculator for lakes, available at: https://sourceforge.net/projects/densitycalc (last access: July 2016), 2014.

Moreira, S., Boehrer, B., Schultze, M., Dietz, S., and Samper, J.: Modelling geochemically caused permanent stratification in Lake Waldsee (Germany), Aquat. Geochem., 17, 265-280, doi:10.1007/s10498-011-9133-4, 2011.

Nixdorf, E. and Boehrer, B.: Quantitative analysis of biogeochemically controlled density stratification in an iron-meromictic lake, Hydrol. Earth Syst. Sci., 19, 4505-4515, doi:10.5194/hess-194505-2015, 2015.

Parkhurst, D. L. and Appelo, C. A. J.: Users guide to PHREEQC (version 2). A Computer program for speciation, batch-reaction, one-dimensional transport, and inverse geochemical calculations, Water-Resources Investigation Report 99-4259, U.S. Geological Survey, 1999.

Pawlowicz, R. and Feistel, R.: Limnological applications of the Thermodynamic Equation of Seawater 2010 (TEOS-10), Limnol. Oceanogr.-Meth., 10, 853-867, 2012.

Pawlowicz, R., Wright, D. G., and Millero, F. J.: The effects of biogeochemical processes on oceanic conductivity/salinity/density relationships and the characterization of real seawater, Ocean Sci., 7, 363-387, doi:10.5194/os-7-363-2011, 2011.

Rinke, K., Kuehn, B., Bocaniov, S., Wendt-Potthoff, K., Büttner, O., Tittel, J., Schultze, M., Herzsprung, P., Rönicke, H., Rink, K., Rinke, K., Dietze, M., Matthes, M., Paul, L., and Friese, K.: Reservoirs as sentinels of catchments: the Rappbode Reservoir Observatory (Harz Mountains, Germany), Environ. Earth Sci., 69, 523-536, doi:10.1007/s12665-013-2464-2, 2013.
Rodrigo, M. A., Miracle, M. R., and Vicente, E.: The meromictic Lake La Cruz (Central Spain). Patterns of stratification, Aquat. Sci., 63, 406-416, doi:10.1007/s00027-001-8041-x, 2001.

Sanchez España, J., Lopez Pamo, E., Diez Ercilla, M., and Santofimia Pastor, E.: Physico-chemical gradients and meromictic stratification in Cueva de la Mora and other acidic pit lakes of the Iberian Pyrite Belt, Mine Water Environ., 28, 15-29, doi:10.1007/s10230-008-0059-z, 2009.

Smith, J. D. and Milne, P. J.: Spectrophotometric determination of silicate in natural waters by formation of small alpha, Greek-molybdosilicic acid and reduction with a tin(IV)ascorbic acid-oxalic acid mixture, Anal. Chim. Acta, 123, 263270, doi:10.1016/S0003-2670(01)83179-2, 1981.

Stabel, H. H.: Chemical composition and drinking water quality of the water from Lake Constance, Arch. Hydrobiol. Spec. Issues Advanc. Limnol., 53, 31-38, 1998.

Tanaka, M., Girard, G., Davis, R., Peuto, A., and Bignell, N.: Recommended table for the density of water between $0{ }^{\circ} \mathrm{C}$ and $40^{\circ} \mathrm{C}$ based on recent experimental reports, Metrologia, 38, 301-309, doi:10.1088/0026-1394/38/4/3, 2001.

Umlauf, L., Burchard, H., and Bolding, K.: General Ocean Turbulence Model. Scientific documentation. V3.2, Marine Science Reports no. 63, Baltic Sea Research Institute Warnemünde, Warnemünde, Germany, 2005.

Vollmer, M. K., Weiss, R. F., Williams, R. T., Falkner, K. K., Qiu, X., Ralph, E. A., and Romanovsky, V. V.: Physical and chemical properties of the waters of saline lakes and their importance for deep-water renewal: Lake IssykKul, Kyrgyzstan, Geochim. Cosmochim. Acta, 66, 4235-4246, doi:10.1016/S0016-7037(02)01052-9, 2002.

von Rohden, C., Boehrer, B., and Ilmberger, J.: Evidence for double diffusion in temperate meromictic lakes, Hydrol. Earth Syst. Sci., 14, 667-674, doi:10.5194/hess-14-667-2010, 2010.

Wüest, A., Piepke, G., and Halfmann, J. D.: Combined effects of dissolved solids and temperature on the density stratification of Lake Malawi (East Africa), in: The limnology, climatology and paleoclimatology of the East African Lakes, edited by: Johnson T. C. and Odada, E. O., Gordon and Breach, New York, 183-202, 1996. 